\title{
Reflexiones hacia una Producción Integral de Artes Escénicas
}

\author{
Raúl S. Algán \\ UADE - Universidad Argentina de la Empresa \\ Instituto de Cs. Sociales y Disciplinas Proyectuales \\ CONICET \\ raulsantiago@algan.com.ar
}

\author{
Brenda S. Berstein \\ UBA - Universidad de Buenos Aires \\ Instituto de Artes del Espectáculo \\ UADE - Universidads Argentina de la Empresa \\ bberst@gmail.com \\ Artículo bajo licencia Creative Commons \\ Atribución 4.0 Internacional (CC BY 4.0) \\ ENVIADO: 2020-03-11 \\ ACEPTADO: 2020-09-13
}

\section{RESUMEN}

Se propone el término Producción Integral de Artes escénicas, realizando un arqueo bibliográfico sobre las definiciones previas de lo que significa producir cultura en el ámbito profesional iberoamericano. Para ello se tiene una mirada integral sobre la acción de producir que contemple arte, negocio y planificación estratégica en sintonía con el mercado y la sostenibilidad de proyectos escénicos. Se incluye al núcleo medular (leitmotiv) y al público objetivo en un lugar central de cualquier proyecto desde una instancia de génesis y se sugiere sumar a las fases habituales una última fase de evaluación.

PALAbras clave

Producción integral, Artes escénicas, Público objetivo, Gestión cultural.

\section{RESUMO}

Propõe-se o termo Produção Integral de Artes Cênicas, realizando uma arqueologia bibliográfica sobre as definições anteriores do que significa produzir cultura no campo profissional ibero-americano. Para isso, é realizado um olhar abrangente sobre a ação de produzir que contemple arte, negócios e planejamento estratégico em sintonia com o mercado e a sustentabilidade dos projetos cênicos. 0 núcleo central (leitmotiv) e o público-alvo estão incluídos em um local central de qualquer projeto de uma instância do genesis, e sugere-se adicionar uma fase de avaliação final às fases usuais.

\section{PALABRAs CLAVE}

Produção integral, Artes cênicas, Públicoalvo, Gestão cultural.

\section{ABSTRACT}

The term Comprehensive Production of Performing Arts is formulated by reviewing previous definitions on what it means to produce culture in an Ibero-American professional framework. For this, we use an integral approach that involves art, business and strategic planning in sync with the market and the sustainability of performing projects. The medullary nucleus (leitmotiv) and an objective audience are included into the central place of any project from its genesis. It is also recommended to add a new stage of evaluation at the end to the regular phases.

\section{KEYWORDS}

Integral production, Performing arts, Target audience, Cultural management. 


\section{INTRODUCCIÓN}

Algunas APROXimaciones PREVIAS AL CONCEPTO DE PRODUCCIÓN ESCÉNICA

La producción de artes escénicas es una actividad que encuentra su origen en la propia constitución del teatro como hecho social. Desde la Grecia Antigua, cuando el teatro se separa del rito y comienza su secularización, aparecen los dos agentes culturales básicos que son necesarios para que haya teatralidad: el intérprete y el público. Pero junto a ellos aparecen también los productores. El rol del productor, aún invisibilizado a lo largo del tiempo, existió desde los inicios de la actividad teatral, al lado de esos primeros agentes y colaborando para que el hecho escénico sucediera. Barthes (1992) describe su existencia al indicar que hubo un "corega [que] se encargaba de instruir y equipar a un coro" (p. 69). Es decir que para que pudiera existir un Tespis y un director que coordinara el quehacer artístico, tuvo que haber un corega ${ }^{1}$ que lo produjese.

Si uno se remite a la definición etimológica de la palabra producción, proviene del verbo latino producěre, que reúne el prefijo pro (delante) con el ducěre (llevar o guiar) y se podría traducir como llevar adelante. Refiere a una acción de idear, trazar o proponer un plan y los medios para la ejecución de un propósito, es decir, desde la ideación hasta el hacer más concreto, implicando instancias de planificación, pero también de realización y evaluación. Presupone una empresa a futuro, algo que se quiere realizar y lograr. Dada esta definición, se observa que fue un largo recorrido el que siguió este agente cultural, pero parece necesario subrayar que siempre que hubo teatro como espectáculo público hubo, tácita o explícitamente, alguien que se ocupara de producirlo. No obstante, aunque gran parte de la sostenibilidad laboral y económica del mercado teatral está vinculada a la labor del productor, en la actualidad su figura no se encuentra totalmente reconocida en la escena latinoamericana.

En general se habla de producir en su acepción aplicada al mundo del espectáculo como la acción de facilitar los recursos económicos y materiales necesarios para la realización de un proyecto artístico y también se lo asocia con coordinar y dirigir su presupuesto (De León, 2012). Evidentemente, la connotación económica es la más fuerte asociando la producción a la productividad y a la relación que conlleva accionando sobre recursos escasos para poder combinarlos de una manera eficaz y eficiente y así dar paso a una creación.

Definiciones más ajustadas del término coinciden en la idea de concebir la producción en tanto proceso de trabajo. Por un lado, se entiende que producir es un proceso "complejo y colectivo donde confluyen ciertas prácticas artísticas, técnicas, administrativas y de gestión llevadas a cabo por un conjunto de individuos de manera organizada, que requieren de diversos recursos para lograr la materialización de un proyecto en un espectáculo" (Schraier, 2008, pág. 17). Se observa en la definición precedente la condición de diversidad de tareas, roles y acciones que hace que no se trate de un proceso simple, aún si se resuelve correctamente y a la vez necesariamente conformado por un equipo de trabajo, un grupo de personas que realizan esas actividades y deben ser coordinadas en su accionar.

En la misma línea, se entiende que producir es un proceso generado "por la actividad conjunta de los equipos de trabajo a través de procedimientos planificados para lograr un producto cultural" (De León, 2012, p. 23). Vuelve a ponerse de relieve en esta definición una mirada de la producción que atiende al proceso extendido

El término proviene del griego y se utiliza para mencionar a aquellos ciudadanos ricos que patrocinaban las obras teatrales, encargándose de costear la puesta en escena sobre todo en cuanto al vestuario y la escenografía. 
en el tiempo, al trabajo colectivo y a la repartición de tareas. Estas últimas características son transversales a los procesos de producción de artes escénicas más allá de los modelos que se apliquen para hacerlo, es decir si se trata de producir desde el Estado, para el mismo, desde de un formato empresarial o independiente ${ }^{2}$.

Desde una mirada Ibérica, siempre con la idea de rastrear trabajos de aproximación al término que hayan trascendido su tiempo, Cimarro (1999) reconoce que un proyecto teatral "requiere la organización de los elementos que harán posible su transformación en actividad profesional" (p. 19) Por su parte, Pérez Martín (2002) menciona que "el trabajo escénico es fundamentalmente un trabajo grupal (...) [donde] es necesaria la división del trabajo pero también la colaboración (...) y la coordinación” (p. 71). Finalmente Navarro de Luis \& Valentín-Gamazo (1998) indican que "la creación y puesta en escena de un espectáculo, requiere que artistas y técnicos trabajen de forma conjunta en el desarrollo del proyecto. El departamento de producción es el eje esencial que coordina todos los aspectos de dicho desarrollo, tarea que requiere una gran dosis de diplomacia y previsión" (p. 33)

En todas las interpretaciones de lo que implica producir subyace que el foco está puesto en el proceso y en la acción unidireccional de quienes llevan adelante el proyecto. Pero aún cabe preguntarse qué relación guarda el diseño de producción con el criterio artístico y de qué forma se vinculan las herramientas para la instrumentalización de un modelo de negocios en las artes escénicas. Se observa que desde las producciones teóricas mencionadas no ha habido a la fecha una propuesta integradora que genere un estadio superador a lo mencionado. Por otro lado, también es pertinente preguntarse qué lugar ocupa el público objetivo, destinatario final de toda producción escénica y poco estudiado y mencionado en las concepciones aquí revisadas. Es decir que el público no se piensa desde la producción como debiera, cuando la recepción de un proyecto debiera estar concebida desde el primer momento de génesis.

Finalmente, resulta interesante concebir la producción como parte integralmente unida a las instancias de representación y a la sustentabilidad en el tiempo que pueda tener un espectáculo ¿Por qué no se propone una mirada integral sobre la acción de producir que contemple arte, negocio y planeamiento estratégico en sintonía con el mercado y la sostenibilidad de los proyectos, incluyendo a los públicos como parte crucial que terminan de constituir un proyecto teatral? De igual forma se postula que sin evaluación concurrente pero también a posteriori del proceso, el mismo no se puede cerrar. Estas preguntas y otras son cuestionadas recurrentemente desde la praxis y pocas veces son abordadas desde la teoría o la reflexión crítica.

Esta salvedad es necesaria porque redunda en las dinámicas de producción puesto que en la primera se prevé la figura de productor general o productor empresario junto con la de productor ejecutivo mientras que en la segunda, por no haber relación de dependencia solo queda la figura de productor ejecutivo (Algán, 2019). Con referencia a los modos de producción valga decir que en Argentina, como en otros países latinoamericanos, coexisten dos formas de organizar el trabajo. La primera que se denomina empresarial por haber un empleador que contrata a artistas y demás personas vinculadas al montaje del espectáculo el cual absorbe el riesgo económico del proyecto. La segunda que se denomina independiente por no haber relación de dependencia y estar apoyada en la voluntad asociativa de agentes culturales que la constituyen.

\section{LA PRODUCCIÓN INTEGRAL}

Como se ha descrito previamente, la producción de espectáculos y particularmente la de artes escénicas no suele ser abordada desde un enfoque integrador. Por lo general, cuando un proyecto escénico es concebido en su origen, la producción es pensada en términos estancos donde lo ejecutivo, lo artístico y lo comercial compiten y se excluyen, primando alguno de los enfoques según el abordaje.

Si bien en el ámbito independiente las áreas mencionadas suelen ser absorbidas, muchas veces, desde un rol unificado y por la misma persona, es necesario abordarlas por separado para construir sobre ellas la idea de producción integral. Es decir que lo integral estriba en primer término en la incorporación del publico objetivo al diseño de producción, luego en pensar a los proyectos escénicos en relación con el entorno sea en términos gerenciales o ejecutivos y por último en mancomunar las visiones sobre la producción para entenderla como un proceso orgánico y común que pueda incluir lo artístico, lo comercial y lo ejecutivo.

Efectivamente se pueden identificar diversos perfiles de productor como lo son ejecutivo, artístico y comercial. El primero es el encargado de desarrollar el pensamiento estratégico y el diseño de producción del proyecto ${ }^{3}$. Es quien suele ocuparse de las actividades vinculadas a los ensayos, la logística y algunas cuestiones claves de la comunicación del espectáculo4. Por su parte, el productor artístico es quien colabora desde el equipo de producción para lograr que la puesta en escena del director se ajuste al presupuesto. Regularmente es quien trabaja con el equipo creativo, procurando compatibilizar criterios para que todos los departamentos trabajen en armonía. Es decir que su tarea genera valor agregado y carga emotiva para el producto por lo tanto es él quien trabaja la idea para que se mantenga fiel al núcleo central del proyecto (leitmotiv) y al público objetivo pensados en la preproducción. A este productor se le solicita el desglose de producción sobre el que se hará el relevamiento de utilería, vestuario y escenografía, abarcando así los rubros técnicos en armonía con el desarrollo artístico planteado. Por último, el productor comercial es quien, comprendiendo el trabajo desarrollado por el productor artístico, busca el posicionamiento del producto. Para ello trabaja entre los presupuestos y su ejecución, por un lado, y los arreglos, canjes, pagos y cobros por el otro. Además, vela por la salud económica y financiera del proyecto a través de la gestión de costos y la búsqueda de fuentes de financiamiento. Una de sus tareas claves es buscar las alianzas estratégicas posibles y la realización del mapa de sponsoreo consistente en relevar y tener claro cuáles pueden ser los interesados (personas físicas, organizaciones, empresas) en participar del proyecto, en función del leitmotiv definido y del diseño de producción.

En este sentido lo esperable es que el productor general o empresario se ocupe del diseño de producción y que el ejecutivo lo ponga en práctica, ejecutando en tiempo y forma las actividades previamente pensadas. En los hechos, esto casi no sucede, lo cual redunda en una sobrecarga de trabajo para ambos.

4 Corresponde aclarar que el trabajo del productor ejecutivo no suple el de asistente de dirección sino que lo complementa. Particularmente en el modo de producción empresarial, regido por la relación de dependencia (según la ley 27203 y el CCT $307 / 73$ ) el productor ejecutivo, como su propia denominación lo indica, ejecuta el plan de producción en los términos que se mencionan. En la Asociación Accidental de Trabajo o Cooperativa su actividad es más difusa porque toca otras áreas de la producción como la comunicación, la presupuestación y los pagos. 
Producción integral de artes escénicas

\begin{tabular}{|c|c|c|}
\hline Producción Ejecutiva & Producción Artística & Producción Comercial \\
\hline Pensamiento estratégico & Valor creativo & Posicionamiento \\
\hline Diseño de producción & $\begin{array}{c}\text { Definición de } \\
\text { Leitmotiv }\end{array}$ & Financiación \\
\hline Logística y comunicación & $\begin{array}{c}\text { Desglose de } \\
\text { producción }\end{array}$ & Presupuestos \\
\hline \multicolumn{2}{|r|}{ Definición del público objetivo } \\
\hline
\end{tabular}

Por lo tanto, dado que el trabajo puede distribuirse por las ramas específicas que se han detallado, se recomienda que siempre haya un equipo de productores y que se prevea la figura de un coordinador de producción. Es este coordinador el que se ocupa de armonizar la labor de los agentes antes mencionados. Aunque esta definición en la práctica queda muchas veces en un plano enunciativo dado que no suele haber recursos económicos ni humanos para que un proyecto tenga desagregado en personas diversas estas actividades, es fundamental comprenderlas por separado para no perder de vista el impacto que tendrán sobre el proyecto escénico que se trabaja, ordenándose alrededor del leitmotiv detectado como núcleo del proyecto.

Aparece como clave este concepto de leitmotiv, que es definido como la reducción del intangible creativo a un concepto, idea fuerza o palabra clave que condensa el espíritu artístico de la obra. Este leitmotiv, palabra de raíz alemana que integra las ideas de guiar y motivar, constituirá el valor central y el núcleo comunicacional del proyecto y será la punta de la flecha con la cual se apunte al público objetivo.

Es necesario aclarar que cuando se menciona al público objetivo, en primera instancia, es necesario comprender que se hace referencia a un concepto o idea, no a una persona o grupo de personas concreto. Es decir que cuando un productor de espectáculos construye el público objetivo de la obra a producir estará pensando en un conjunto de variables que agrupadas construirán una masa abstracta y homogénea de rasgos, una aproximación idealizada de quienes luego serán, si todo sale bien, los verdaderos espectadores que concurran a ver la propuesta. Se piensan así, variables etarias, geográficas o de género, así como otras de orden más cualitativo como puede ser gustos, prácticas culturales o estilos de indumentaria. De hecho, sobre esas variables es recomendable pensar al menos un público objetivo primario y uno secundario que lo amplíe.

Entonces, reconocer el leitmotiv de ese intangible creativo, trazar el diseño de producción, coordinar a los grupos humanos implicados en esas tareas y realizar el plan de comunicación consecuente para lograr interpelar a ese público objetivo es la labor verdadera de la producción integral. Evidentemente, la correcta definición del leitmotiv y la construcción de público objetivo no redundará necesariamente en que el proyecto sea un éxito económico porque esta actividad no tiene manera de contar con esa certeza, pero sí garantiza un correcto funcionamiento de las instancias/ fases que nos llevan de la génesis de una idea a su estreno y representación, minimizando el riesgo lo máximo posible. Cabe entonces destacar que en la producción escénica el éxito no está mediado por la rentabilidad económica exclusivamente. Por el contrario, la situación de génesis es clave porque alli es donde se trazan los objetivos a cumplir con el diseño de producción y el éxito o no del proyecto se medirá en función de si esos objetivos fueron satisfechos o no. Es decir que muchas veces puede suceder que un proyecto sea exitoso aún cuando no presenta rentabilidad.

Por ello, si el diseño de producción es orgánico el espectáculo será sino rentable, al menos sostenible. Ahora bien ¿qué se entiende por orgánico? Básicamente que los recursos disponibles para la producción sean utilizados de manera eficaz y eficiente. La importancia de lograr que el espectáculo sea sustentable subyace en la propia dinámica de la producción integral porque la misma busca que perdure más allá del estreno. Por lo expuesto, lograr que un proyecto escénico sea sostenible impacta en la misma curva de utilidad que el servicio cultural tiene haciendo que se extienda tanto como sea posible. Es decir que al estreno y la temporada inicial en una primera temporada de funciones, idealmente podrían sumarse futuras representaciones: temporadas adicionales, giras dentro y fuera del país, festivales (no necesariamente en ese orden), pero también una mirada de tipo 360 grados del negocio, donde puedan incluirse otras cuestiones como merchandising, grabaciones audiovisuales para distintas ventanas de exhibición, adaptaciones o versiones editoriales o fílmicas, material adicional en redes sociales, crecimiento a partir de la historia o los personajes en proyectos subsidiarios, etc.

Las artes escénicas conservan aún la impronta de trabajo más artesanal del sector cultural. Es un arte vivo e irrepetible donde el encuentro que provocan hace que la expresión suceda una única vez, cuando hay función. Pero también están insertas en un mundo global, en donde la aceleración tecnológica producida en los últimos años y los cambios socioculturales en el consumo y la recepción que eso genera, deben ser incluidos en nuestras metodologías de producción. Nuestra mirada integral, incluye necesariamente estas cuestiones. 


\section{Algunas herramientas para la génesis}

La propuesta de pensar la producción escénica desde los primeros momentos de encuentro se cimenta en la necesidad de no perder de vista que aunque el trabajo de la producción no es propiamente artístico, definitivamente es creativo. Es decir que cada proyecto escénico se presenta ante el productor como una incógnita a resolver y de ello se desprende que cada uno requiere una estrategia de abordaje diferente. Entonces cuando un productor escénico comienza a transitar la génesis de un proyecto, comienza también a diseñar la estrategia general de producción combinando todas las opciones posibles que devienen de la detección de un leitmotiv central, del análisis contextual que elabore, de los recursos con los que cuente, del público objetivo al cual esté orientado el proyecto y de su criterio personal ${ }^{5}$, entre otras cuestiones relevantes.

Entonces, el productor marca un punto de inicio o génesis, donde el proyecto se empieza a gestar. Se trata de un primer encuentro de los agentes culturales, la puesta en marcha de aquellos cuya labor se orienta a propiciar "las condiciones para que otros creen o inventen sus propios fines culturales" (Coelho, 2009, p. 40). Independientemente del nombre que reciba, todo proyecto comienza con una primera idea, un instante de movilización emocional o intelectual que es la chispa original de la cual nace todo el proyecto a ser producido. En este momento de génesis las distintas lógicas y miradas están integradas en una gran incógnita que debe empezar a despejarse y también en una gran energía concentrada que como el big bang se despliega, sumando personas dentro de los equipos, definiendo y ordenando recursos y variables para que el proyecto pueda comenzar a gestarse. En otras palabras toda producción "debería contar con una etapa inicial en la que se analicen - primero de forma aproximada, luego más exhaustivamente- aspectos referidos a la génesis del proyecto" (Schraier, 2008 , p. 43). Hay algo allí de los tiempos justos, del momento y del equipo y su motivación, en conjunto con el contexto. Un cúmulo de situaciones deben darse y combinarse para que un proyecto decida ser encarado. Esta génesis, es decir el momento en el cual el promotor del proyecto sea este un actor, un director, un productor o cualquier otro agente cultural del sector, se siente interpelado por la poética de un texto o su propuesta creativa.

Aquí además se logran los primeros acuerdos de voluntades entre el equipo central de trabajo y se deberían comenzar a responder los interrogantes centrales que, según Schraier (2008), son el corazón de todo proyecto: ¿qué hay que hacer? ¿cómo? ¿con qué? ¿quiénes lo harán? ¿quiénes lo supervisarán? ¿quién coordinará? ¿cuándo? ¿dónde? ¿cuánto costará? ¿para quienes se lo hace? El proyecto, entonces, permite ponerse en acción, ya sea desde la ideación o desde el hacer más concreto, implicando instancias de planificación pero también de implementación concreta, es decir de realización. Y se debe sumar, también, una instancia de evaluación, concebida desde un inicio para saber qué se quiere medir y cómo hacerlo.

El criterio personal incluye la formación, la experiencia y algo del propio estilo y personalidad, pero sobre todo la ética de trabajo que el productor puede (y debe) mantener en el tiempo. La producción integral debería incluir también los aspectos éticos y deontológicos del rol.
Así, en primera instancia es necesario definir que "Los objetivos responden a qué es lo que se quiere lograr" (De León, 2012, p. 41) es decir, que son los primeros en materializar el rumbo que va a tomar el proyecto con relación a los propósitos de quienes son sus promotores principales. La principal diferencia entre los propósitos y los objetivos es que los primeros responden a anhelos motivaciones y los segundos son, a grandes rasgos, alcanzables y específicos. La polémica estriba en cómo son concebidas las metas, es decir, si son superadoras de los objetivos o, por el contrario, una forma de llegar a cumplirlos. En este sentido una visión indica que "todo proyecto está compuesto por una serie de metas que se deben cumplir para alcanzar los objetivos propuesto" (Schraier, 2008, p.48) o concibe a las metas como "los peldaños que nos llevan a conseguir a más largo plazo los propósitos últimos" (Pérez Martín, 2011, p. 42), mientras que otra sostiene que los objetivos "Son una serie de ideas específicas que complementan con detalle las metas planteadas. Son una lista de la forma específica en que se alcanzarán las metas" (De León, 2012, p. 41). Por lo tanto se observa que no hay consenso al momento de definir qué son lo objetivos y qué función cumplen en el diseño de producción.

Se considera que los objetivos pueden dividirse en generales y específicos, mientras que las metas son la cuantificación concreta de un objetivo, es decir, la posibilidad de convertirlos en instancias medibles que puedan por tanto ser alcanzadas (en mayor o menor grado, de manera completa o parcial). Es decir que, si un objetivo de la producción es ganar una fuente de financiamiento público, la primera meta es trazar un mapeo de fuentes de financiamiento públicas y sus consecuentes convocatorios. La siguiente meta es reunir la documentación necesaria para hacer la solicitud. Luego viene una instancia de presentación de documentos. Se observa que cada acción esta orientada a una meta, cada meta a un objetivo y cada objetivo a un propósito. En cierto modo, hacer planificación estratégica es considerar estas cuestiones en un plan de acción. El proyecto es una forma de vehiculizar las necesidades y los consecuentes objetivos que se planteen en el diseño de producción.

También dentro de ese momento inicial, aparece una instancia de diagnóstico no sólo del proyecto sino del entorno en el que éste se insertará, que servirá para comprender cabalmente la viabilidad global del proyecto. Si se concibe la producción de artes escénicas en su carácter integral, es decir comprendida la actividad como un todo que integra aspectos creativos, logísticos y económicos, es preciso comprender que en tanto tal, los diseños de producción son cristalizadores de la impronta cultural que los circunda y es fundamental integrar el territorio y las políticas culturales que afectan la realidad local en donde el mismo se emplaza. Si se piensa que el teatro es "esencialmente territorial y localizado cada vez que acontece en un punto del planeta, el teatro es una reunión de cuerpos presentes, y esos cuerpos acarrean al territorio del acontecimiento la 'geografía humana' de todo el mundo" (Dubatti, 2012, p. 9), cabría preguntarse cuál es la escala con la cual correlacionar los diseños de producción y la estética que ellos trabajan. No es lo mismo producir artes escénicas en Latinoamérica que en otros continentes y mismo dentro de nuestro entorno, cada país y cada ciudad tiene sus propias realidades. Cada diseño de producción debería poder 
reflejar la particularidad del territorio en el que su desarrollo tenga lugar.

En ese contexto, es importante destacar algunas herramientas que le sirven al productor integral de artes escénicas para realizar el diagnóstico apropiado. Aquí sólo se describen brevemente tres de ellas, ya que su conocimiento en profundidad excede las condiciones de escritura del presente artículo: son en análisis PESTEL, el modelo de rivalidad ampliada conocido como las cinco fuerzas de Porter y el FODA (también conocido como DAFO o SWOT).

El primero es una simple regla mnemotécnica con las iniciales de aquellos factores del entorno general que pueden llegar a afectar el proyecto: políticos, económicos, socioculturales, tecnológicos, ecológicos y legales. Por ejemplo, entender los calendarios escolares o comerciales de cada país en el que se trabaja, porque puede suceder que una gira esté muy bien planeada, pero sin estas consideraciones se arme justo para feriados significativos en donde las personas no concurren al teatro en ese país. 0 que regulaciones legales específicas no permitan realizar funciones en espacios públicos o después de determinada hora, etc.

Para un análisis del entorno más específico, es decir, un análisis de la competencia, se puede utilizar la matriz de cinco fuerzas de Porter con su modelo de rivalidad ampliada. Allí se analiza tanto la competencia directa, como el diferencial que se tiene con ella a través de determinada ventaja competitiva. Por ejemplo qué otras salas o compañías tienen funciones en espacios cercanos o con temáticas similares y cuál es la diferencia que un espectáculo plantea con relación a otro. De igual manera se consideran los poderes de negociación de proveedores y consumidores, teniendo en cuenta qué capacidad de elección tienen los participantes en esa cadena productiva. No es lo mismo si el espectáculo es el único que se presenta en esa plaza ese fin de semana que si compite con otros diez por la atención del público o por la cobertura de proveedores de iluminación. Por último, se consideran los posibles entrantes potenciales que hoy no son competencia, pero podrían serlo en breve y los productos sustitutos, es decir, aquellos que satisfacen para el mismo segmento de consumidores una necesidad similar, pero con otra tecnología. En este último punto es interesante entender que el público que concurre al teatro también puede elegir otras propuestas como el cine, un restaurante o quedarse en su casa disfrutando de otro tipo de entretenimiento online, por ejemplo.

Por último, el FODA es un esquema sencillo que permite visualizar las fortalezas y debilidades del proyecto, consideradas internamente con lo que se tiene y lo que no, así como las oportunidades y amenazas con relación al entorno, tanto general como específico ya analizado con las herramientas anteriores mencionadas.

Finalmente, en cuanto al análisis del proyecto específico en cuanto a su sustentabilidad, rentabilidad o potencialidades, deberá poder estimarse su capacidad de generar ingresos y afrontar los costos implicados. Queda claro que "para que exista un espectáculo teatral, hay un costo a afrontar, más allá de si lo cubre el creador, una compañía, el sector público desde alguna de sus instituciones, marcas asociadas como sponsors, audiencias que pagan su entrada en taquilla de manera particular u otros.
Es decir, para que un proyecto sea sustentable, hay una lógica económica implicada implícita o explícitamente por detrás (...) que integran lo que llamamos genéricamente un modelo de negocios, más allá de su objetivo principal sea "hacer un negocio" en tanto buscar rentabilidad o no." (Berstein, 2019, p. 37). En ese sentido, una de las herramientas más utilizadas para visualizar modelos de negocios es la que propone Osterwalder y Pigneur (2010) conocida como lienzo de negocios o esquema CANVAS. Se trata de una combinación de nueve bloques ${ }^{6}$ que muestran la lógica de cómo un proyecto busca cumplir sus objetivos. Estos nueve bloques cubren las cuatro áreas principales de un negocio: clientes, oferta, infraestructura y viabilidad financiera. El modelo de negocios funciona como un plano, una herramienta muy útil para pensar, concebir, implementar y evaluar el funcionamiento de un negocio. Si bien fue originalmente concebido para su aplicación en empresas y emprendimientos de diversa índole, es ideal para ser aplicado desde el inicio mismo de cualquier proyecto escénico ${ }^{7}$.
6 Estos son: 1) Segmentos de mercado/ Clientes / Consumidores, 2) Propuesta de Valor, 3) Canales, 4) Relaciones con clientes/ usuarios, 5) Modelo de ingresos, 6) Recursos Claves, 7) Actividades claves, 8) Alianzas estratégicas, 9) Estructura de costos.

7 Al respecto, puede consultarse Berstein, B. (2019) "Algunas herramientas de negocios para la gestión y producción de artes escénicas en el ámbito ibero-americano" en Dubatti, J. (coord) Producción artística teatral, Santa Cruz de las Sierras, Bolivia: Apac. ISBN 978-99974-263-0-7 


\section{LAS FASES DE UN PROYECTO}

Si se atiende a la definición etimológica de la palabra proyecto se puede decir que viene del latín pro-iectus, es decir, de la acción de arrojar hacia adelante. También refiere más allá de la acción física, al idear, trazar o proponer un plan y los medios para la ejecución de un propósito, es decir, el pensamiento de ejecutar algo y el plan de trabajo para lograrlo. Presupone una empresa a futuro, algo que se pretende realizar y lograr.

El proyecto, entonces, permite ponerse en acción, ya sea desde la ideación o desde el hacer más concreto, implicando instancias de planificación, pero también de implementación concreta, es decir, de realización. Si bien remite a un momento actual en el que, voluntariamente se planifican acciones que van a ser realizadas a futuro, implica necesariamente y desde un inicio, la capacidad de entender mejor a nivel diagnóstico la situación pasada para anticipar los desarrollos venideros. Y se debe sumar, también, una instancia de evaluación, concebida desde un inicio para saber qué se quiere medir y cómo hacerlo.

Así que, si bien hay diferentes definiciones de proyecto todas coinciden de alguna forma en las siguientes características: implican una planificación con diverso grado de detalle y proyección para la ejecución de algo, es decir, asociada a esfuerzos de cambio. En este sentido, cada proyecto es único y su planteo consiste en una alternativa novedosa, original y autónoma para la resolución de determinada necesidad o problema, o acorde a determinada percepción de valor que pueda tener un público particular; involucran determinada combinación de recursos materiales (físicos, de infraestructura, financieros) y humanos en una organización temporal limitada a un cierto período de tiempo; poseen un grado de riesgo o de incertidumbre, ya que son una apertura a futuro, promueven el cambio y acciones que nunca se hicieron hasta entonces de esa manera; presuponen un conjunto de actividades interrelacionadas y coordinadas para el logro de un propósito o de objetivos propuestos, es decir, que constituyen un proceso con distintas etapas para obtener un resultado.

Entonces se define que cualquier proyecto bien pensado e implementado debería tener una instancia previa de encuentro y de acuerdo de voluntades, a la que ya se ha referido previamente como génesis y luego incluir las etapas o fases de diseño, implementación (o ejecución), acción y evaluación.

\begin{tabular}{|c|c|}
\hline GÉNESIS & Encuentro \\
\hline PREPRODUCCIÓN & Diseño \\
\hline PRODUCCIÓN & Implementación \\
\hline REPRESENTACIÓN & Acción/ Explotación \\
\hline EVALUACIÓN & Registro y memoria. \\
\hline
\end{tabular}

Cabe mencionar, a su vez, que esas etapas o fases se presentan adyacentes unas a otras porque cada una está atravesada por una actividad rectora que rige el patrón de conducta de toda la instancia y allí se integran diferentes procesos. Esa es la propia definición de fase, como estados diferenciados por el que pasa un proceso en desarrollo. Es decir que no es conveniente superponerlas porque al hacerlo se pueden producir conflictos entre los procesos de producción que perturban la armonía de las variables. Entonces, cada fase es adyacente, cada una está mediada por una actividad principal que agrupa la dinámica de trabajo de ese momento del proyecto y cada fase se puede dividir en procesos. Estos últimos son simultáneos y es en esa condición donde arraiga la complejidad de la producción escénica puesto que un atraso en alguno de ellos supone una demora en los demás. Finalmente hay hitos de control que se distribuyen estratégicamente a lo largo del tiempo que dura el proyecto con el objeto de controlar potenciales desviaciones. 


\section{LA PREPRODUCCIÓN, LA PRODUCCIÓN Y LA} REPRESENTACIÓN

Por lo tanto, superado ese momento cero, todo proyecto escénico comienza, como bien lo han establecido Schraier (2008) y De León (2012), por esa primera fase llamada preproducción. Entonces comienza esta primera fase donde se produce el diagnóstico de las acciones necesarias para la materialización del proyecto. Se propone pensar en un diagnóstico, más que en un análisis como lo propone Schraier (2008) porque el primero presupone, además de un análisis, una estrategia para abordar la cuestión. Mientras la situación de análisis es meramente evaluativa y no presupone necesariamente un plan de acción a seguir, del diagnóstico se deduce el diseño de producción.

A la fase de preproducción, donde la principal actividad es la que se acaba de mencionar y donde se llevó a cabo todo el diseño estratégico que será el molde del proyecto, le sigue la fase de producción. En esta, la principal actividad es la ejecución y como tal presupone un salto del escritorio al campo, es decir del pensar al hacer. En esta fase se ejecuta el diseño de producción con sus procesos específicos los cuales están en diálogo con los procesos de la fase anterior. Por ejemplo, en la preproducción tiene que haber un proceso de presupuestación estimada donde se construyen los presupuestos, flujo de fondos y estudio de viabilidad económica. En la producción, habrá un proceso administrativo y contable donde eso que se proyectó erogar y cobrar se ejecuta realmente y donde se puedan controlar y ajustar esos cálculos iniciales. Entonces en esta fase, que puede consumir menos tiempo pero es más intensa, el productor integral deberá repartir su tiempo entre ejecutar el proyecto de producción concebido, detectar posibles desviaciones y rectificarlas y atender a la correcta circulación de la información entre los agentes culturales que intervienen en el proyecto para que no haya demoras ni malos entendidos que puedan afectar la fecha y condiciones de estreno.

Regularmente, a la tercera fase se la llama explotación porque está concebida desde una mirada netamente comercial que entiende a las funciones que hace un proyecto escénico como un producto cultural. Se propone pensarlo más bien como un servicio cultural que como un producto porque la representación escénica no se agota como puede agotarse un libro o un disco que al ser producido por una cantidad de unidades determinada al venderse la última se agota el producto. Por el contrario, el teatro es un servicio que considera a los espectadores como usuarios del mismo y que se ofrecerá en tanto haya personas dispuestas a pagar la entrada por vivir la experiencia de la función ofrecida. En tanto servicios cultural no se agota porque siempre se puede ser haciendo funciones y porque cada una es un evento único e irrepetible que se apoya en la idea de convivio desarrollada por Dubatti (2012).

Se propone entonces entender a esta fase como de representación y no como una de explotación porque la razón de ser de ella misma la conforma la secuencia de funciones que se logren. La actividad principal de esta fase es lograr que el espectáculo sea sustentable para que no dependa exclusivamente de la publicidad o de la prensa. Esto se logra solo si el diseño de producción logró unir al servicio cultural con su público objetivo instrumentando los medios de comunicación, fortaleciendo la identidad cultural o valor agregado de la propuesta y optimizando los recursos disponibles. Sustentar apunta a que el proyecto tenga vida propia, mantener genera una dependencia que lejos de fortalecer la propuesta la debilita. Esta fase comienza con el estreno y concluye cuando la obra baja definitivamente de cartel. Esto es importante de ser comprendido cabalmente porque una obra puede hacer muchas temporadas, giras, participar de festivales y en tanto se trate siempre del mismo montaje, incluso aunque varíen los actores, estará siempre en la fase de representación. Entonces, aunque se puedan disparar micro procesos de producción para adecuar la obra a un festival o a una nueva sala, nunca se abandona la fase porque la obra se sigue representando con el mismo montaje concebido en la preproducción. 


\section{UNA FASE FINAL Y NECESARIA}

Hasta aquí se ha recuperado la concepción histórica que se ha tenido de la producción teatral: un entramado de actividades consideradas de forma tal que tornen rentable un espectáculo. Se propone, junto a la idea de producción integral que se ha trabajado a lo largo de este artículo agregar una cuarta fase a la secuencia punteada anteriormente denominada evaluación. En esta, se debe proceder al análisis de las gestiones llevadas a cabo y a su consecuente resultado procurando integrar cuestiones artísticas y comerciales. Es fundamental que el análisis sea global para no desatender a ninguno de los resultados ni aprendizajes que el proyecto haya generado. Es necesario que circule entre los agentes culturales vinculados al proyecto un dossier o carpeta donde están plasmados todos los indicadores que hayan sido evaluados y que esta memoria del proyecto sea considerada como resultado, también, de la labor del productor integral.

Por supuesto antes de elegir esos indicadores, es necesario acordar qué aspectos se quieren monitorear y evaluar, ya que esos criterios orientarán la elección de las mediciones y las metodologías para realizarlas. En ese sentido, los indicadores mencionados, para que sean efectivos deben estar concebidos desde el inicio de los proyectos, en la instancia de planificación, aunque recién vayan a ser utilizados y relevados al final de la misma. Es interesante no pensar la evaluación en términos estrictamente cuantitativos sino tratar de combinar éstos, con aspectos cualitativos. Saber la cantidad de espectadores reales, o el precio promedio de entrada, es tan importante como la crítica que nos haya realizado un importante medio o la nominación a un premio que se haya podido recibir, entre otros aprendizaje que se puedan ir registrando.

Es importante destacar también que, habitualmente en muchos países latinoamericanos cuyos contextos están signados por la incertidumbre y la inestabilidad, tanto a nivel político como económico y social, los productores deban tener controles constantes. Estos fueron mencionados anteriormente como hitos de control y son claves para garantizar la buena performance del plan de producción. Los hitos permiten ir ajustando sobre la marcha esas desviaciones, pero no suplantan la fase de evaluación que debe hacerse al final del ejercicio y con una impronta de memoria.

En esta fase también, y sobre todo dados los plazos que las fuentes de financiamientos públicas suelen manejar, se lleva adelante la rendición de los subsidios o ayudas económicas que el proyecto hubiera obtenido. En este punto es importante no dejar de atender a las posibles contraprestaciones que las fuentes soliciten porque pueden redundar en que la compañía se vea afectada en la realización de funciones no remuneradas. Esta fase comienza cuando la obra baja definitivamente de cartel y concluye con la última reunión del equipo o generación de la memoria definitiva del proyecto. 


\section{RefLeXIONES finALES}

Se considera al sector de la cultura, y dentro de él a la producción en todos los lenguajes artísticos posibles, un sector noble porque su actividad redunda en un impacto sobre las económicas conexas. Bonet (2007) reconoce que este efecto multiplicador hace que las actividades conexas a la cultural se dinamicen conforme esta se ve estimulada. En este sentido, se espera que la gastronomía, el transporte o la indumentaria, entre otros sectores similares, vean un impacto positivo en sus dinámicas si hay cerca un centro cultural, un teatro o un cine. Este contexto debe ser considerado por el productor integral debido a que su proyecto se verá inmerso en estas sinergias que son también condicionamientos para el espectador, ya que la salida teatral puede implicar un café previo, una cena posterior, un estacionamiento para el auto propio o el pago de un taxi para el regreso a su casa para no aguardar el transporte público, entre otras. Por eso al momento de considerar los horarios de función, los precios de las entradas y demás variables, es fundamental pensar el proyecto de manera integral con el entorno en el que se mueve. La condición de integral de una producción, debe considerar los aspectos vinculados a las áreas de trabajo (arte, negocio, logística) pero también al proyecto en su entorno como condicionante y condicionado, a la vez, por el proyecto.

Así, la historia de la producción escénica ha ido avanzando acorde a los diferentes momentos sociales: de una labor funcional a la polis y al sector público como lo fue en la Grecia antigua, a un agente profesionalizado que genera valor para una sociedad contemporánea. En ese camino, el agente cultural que se denomina productor integral de artes escénicas se encuentra en el proceso de profesionalización que lo empuja a ser más competitivo. La efervescencia de carreras de grado y posgrado vinculadas a la gestión cultural son fieles testigo de este proceso. En este sentido, una mirada latinoamericana que de cuenta de las realidades que atraviesan los sectores culturales de nuestros países redundará en que los productores integrales de artes escénicas comprendan mejor las dinámicas de los sectores económicos en los que está inserta nuestra actividad y puedan desempeñarse de manera cada vez más efectiva y eficiente.

De lo expuesto, se observa que muchas veces teoría y práctica se ven mutuamente condicionadas siendo la segunda la que suele imponerse. Los tiempos de reflexión no siempre son los mismos que los de la acción y eso torna más difícil la integración de los espacios. Se destaca en este artículo la necesidad de comenzar a pensar y reflexionar en profundidad sobre nuestro quehacer. La producción integral como aquí ha sido concebida incluye necesariamente la capacidad de pensarse a sí misma, conceptualizar su quehacer, dejar registro y compartirlo con otros. Se propone un quehacer reflexivo del que podrán surgir nuevos modelos de pensamiento cultural y de producción integral de artes escénicas. 
AlgÁN, R. S. (2019). Mercado teatral y cadena de valor. Caseros, Argentina: RGC Ediciones.

BARThes, R. (1992). Lo obvio y lo obtuso. Buenos Aires: Paidós.

Bonet, LL. (2007). El lugar de la economía de la cultura como disciplina contemporánea. En Economía de la cultura. (pp. 17-34). Buenos Aires, Argentina: Observatorio cultural. Posgrado en Administración de las Artes del Espectáculo.

Baumol, W. J. \& Bowen, W. G. (1966). Performing Arts. The Economic Dilemma. New York, EE. UU.: Twentieh Century Fund.

Cimarro, J. (1999). Producción, gestión y distribución del teatro. Madrid, España: Fundación Autor.

Coelho, T. (2009). Diccionario crítico de la política cultural. Cultura e Imaginario. Barcelona: Gedisa.

De LEón, M. (2012). Producción de espectáculos escénicos. Caseros, Argentina: RGC Libros.

BERSTEIN, B. (2019) “Algunas herramientas de negocios para la gestión y producción de artes escénicas en el ámbito ibero-americano” en Dubatti, J. (coord) Producción artística teatral, Santa Cruz de las Sierras, Bolivia: Apac. ISBN 978-99974-263-0-7

DubatтI, J. (2012). Introducción a los estudios teatrales. Buenos Aires, Argentina: Atuel

Ley Nacional Repúbica Argentina N² 27.203 (2015, 28 De octubre). Boletín Oficial 33265, noviembre 262015 .

Navarro de luis, G. \& Valentín-Gamazo Garmendia, T. (1998). Planificación, producción y promoción teatral. Sevilla, España: Junta de Andalucía, Consejería de Cultura.

Osterwalder, A. \& Pigneur, Y. (2010) Generación de Modelos de Negocio. New Jersey: John Wiley \& Sons, Inc.

Pérez Martín, M. Á. (2002). Gestión de proyectos escénicos. Madrid, España. Ñaque Editora

Pérez Martín, M. Á. (2011). Gestión de salas y espacios escénicos. Madrid, España. Naque Editora

SChRAIER, G. (2008). Laboratorio de producción teatral 1. Buenos Aires, Argentina: Atuel. 